\title{
Avaliação de novos depósitos de argilas provenientes da região sul do Amapá visando aplicação na indústria cerâmica
}

\section{(Evaluation of new deposits of clays from the southern region of Amapá for application in the ceramic industry)}

\author{
A. L. Silva, C.B.B. Luna,A.C. Chaves, G.A. Neves \\ Programa de Pós-Graduação em Ciência e Engenharia de Materiais, CCT, UFCG, R. Aprígio Veloso 882, \\ Campina Grande, PB, Brasil 58429-140 \\ adrianolimadasilva@hotmail.com,alexsandrachaves@hotmail.com,brunobarretodemaufcg@hotmail.com, \\ gelmires.neves@ufcg.edu.br
}

\begin{abstract}
Resumo
A indústria cerâmica figura entre as cadeias produtivas mais importantes do estado do Amapá, tanto na geração de divisas, quanto na de empregos. O presente trabalho teve como objetivo caracterizar novos depósitos de argilas provenientes da região sul do Amapá, visando aplicações nas indústrias cerâmicas. As argilas inicialmente foram submetidas às caracterizações física, química, mineralógica e térmica. Posteriormente, foram confeccionados corpos de prova por prensagem uniaxial, sendo aplicada prensagem em duas etapas de 13,4 e $20 \mathrm{MPa}$. As amostras foram secas em uma estufa a $110^{\circ} \mathrm{C}$, e submetidas à queima em 850,1000 e $1200^{\circ} \mathrm{C}$. Foram determinadas as propriedades físico-mecânicas: retração linear de queima, absorção de água, porosidade aparente, densidade aparente e resistência à flexão, bem como a quantificação das fases cristalinas e a evolução mineralógica após queima. Os resultados evidenciaram que as argilas são constituídas por caulinita, quartzo, mica e esmectita. Em relação às propriedades físico-mecânicas, verificou-se que cinco argilas são adequadas para uso como refratários densos e uma para cerâmica vermelha.
\end{abstract}

Palavras-chave: argilas, novos depósitos, caracterização, propriedades.

\section{Abstract}

The ceramic industry is among the most important productive chains of the Amapa state, both in the capital and jobs generation. The objective of the present work was to characterize the new clay deposits from the south region of Amapá, aiming its application in the ceramic industry. Initially, the clays were submitted to physical, chemical, mineralogical and thermal characterizations. Afterwards, specimens were prepared by uniaxial pressing, applying two steps pressing of 13.4 and $20 \mathrm{MPa}$. The samples were dried in an oven at $110^{\circ} \mathrm{C}$, and submitted to firing at 850,1000 and $1200{ }^{\circ} \mathrm{C}$. The determined physico-mechanical properties were: linear firing shrinkage, water absorption, apparent porosity and flexural resistance, as well as post-firing mineralogical evolution. The results showed that the clays are composed by kaolinite, smectite, quartz and mica. In relation to the physico-mechanical properties, it was verified that five clays are suitable for use as dense refractories and one for red ceramics.

Keywords: clays, new deposits, characterization, properties.

\section{INTRODUÇÃO}

A indústria cerâmica brasileira tem grande importância para o país, tanto na geração de divisas como na geração de empregos [1]. O Brasil é um grande produtor de argilas para a indústria de cerâmica, em virtude do grande número de jazidas e empresas espalhadas por todo o país, consumindo cerca de 70 milhões de toneladas de matérias-primas por ano. Assim sendo, estima-se que a indústria cerâmica brasileira tenha uma participação de aproximadamente $1 \%$ do PIB [2, 3]. A argila é um material natural, terroso, de granulação fina, que geralmente adquire quando umedecida com água certa plasticidade, bem como resistência mecânica após ser submetidas a um tratamento térmico adequado. Além disso, são materiais formados essencialmente por silicatos hidratados de alumínio, ferro e magnésio, denominados argilominerais [4]. Geralmente, as argilas são materiais muito heterogêneos, cujas propriedades dependem da sua formação geológica e da localização da extração. Em geral, observa-se grande complexidade e variabilidade composicional em argilas extraídas de jazidas distintas, em decorrência de suas características e particularidades geológicas. Sendo assim, evidencia-se a necessidade de pesquisas que buscam a caracterização das argilas dessas jazidas, a fim de se poder extrair o real potencial tecnológico [5-7]. Além disso, é importante conhecer a mineralogia das argilas para que se possa utilizá-las adequadamente em diversos processos industriais. A qualidade dos produtos cerâmicos está ligada principalmente às propriedades tecnológicas e mineralógicas das argilas empregadas, tais como: granulometria, plasticidade e composição mineralógica, dentre outros vários fatores $[8,9]$. 
No estado do Amapá, as indústrias cerâmicas têm grande importância socioeconômica, porém ainda é bastante recente a implantação destas indústrias, não conseguindo atender o mercado local [10]. Por isso, tem-se incentivado a busca de novos depósitos com o intuito de suprir as novas indústrias que estão sendo implantadas no estado. Por outro lado, o estado segue, à regra do restante do país, não tendo o conhecimento adequado das características físicas, químicas e mineralógica das matérias-primas utilizadas por essas indústrias cerâmicas, apesar dos esforços no sentido de contornar essa lacuna tecnológica no estado do Amapá $[11,12]$. Sabe-se que o conhecimento das características das matérias-primas contribui diretamente para a melhoria das propriedades do produto final, e possibilita ao fabricante flexibilidade, redução de custos de produção, bem como aumento no valor agregado de seu produto. Sendo assim, o conhecimento das características das argilas tem grande interesse tecnológico e comercial [13-15]. O objetivo desse trabalho foi realizar caracterizações tecnológicas de seis novas argilas cujas jazidas estão localizadas na região sul do estado do Amapá.

\section{MATERIAIS E MÉTODOS}

As amostras de argilas analisadas foram provenientes de novas ocorrências na cidade de Laranjal do Jari localizada no estado do Amapá, extraídas da reserva em 6 níveis de profundidade distintas, sendo denominadas: A, B, $\mathrm{C}, \mathrm{D}, \mathrm{E}$ e F. Inicialmente, as argilas foram secas em estufa a $60{ }^{\circ} \mathrm{C}$ durante $24 \mathrm{~h}$. Posteriormente, foram submetidas ao processo de beneficiamento através de moagem em moinhos de martelo e galga com objetivo de transformálas em pó. Após moagem as argilas foram passadas em peneira ABNT $\mathrm{n}^{\circ} 200(0,074 \mathrm{~mm})$, e em seguida foram submetidas às caracterizações física, química e mineralógica. A caracterização das amostras das argilas foi efetuada por meio das seguintes técnicas: análise granulométrica por espalhamento laser (Cilas, $1064 \mathrm{~L} / \mathrm{D}$ ); análise química por fluorescência de raios X (Shimadzu, EDX 720); limites de liquidez e de plasticidade, como base nas normas da ABNT [16, 17]; análise termogravimétrica (ATG) e análise térmica diferencial (DTA, sistema de análise térmica simultânea Shimadzu, TA $60 \mathrm{H}$ ), com taxa de aquecimento de $12,5^{\circ} \mathrm{C} / \mathrm{min}$ em atmosfera de ar (temperatura máxima $1000{ }^{\circ} \mathrm{C}$ e padrão na DTA de óxido de alumínio calcinado); e difração de raios X (Shimadzu, D6000) com radiação $\mathrm{CuK} \alpha(40 \mathrm{kV} / 30 \mathrm{~mA})$ e velocidade do goniômetro de $2{ }^{\circ} \mathrm{C} / \mathrm{min}$ e passo de $0,02^{\circ}$, na faixa de 5 a $60^{\circ}$.

As massas semissecas foram conformadas por prensagem. Foi adicionado um teor de umidade de 7,0\% da massa total da argila e, posteriormente, homogeneizada no moinho de bolas por $24 \mathrm{~h}$. Após homogeneização, as massas foram conformadas por prensagem uniaxial (Servitech, CT-335), sendo aplicado uma pré-prensagem de 13,4 MPa e, posteriormente, uma prensagem de 20,0 MPa para obtenção de corpos de prova retangular, com 50 x $15 \mathrm{~mm}$ de dimensões. Foram confeccionados 30 corpos de prova para cada composição. Após a etapa de conformação, os corpos de prova foram sinterizados em forno elétrico a 850 , 1000 e $1200{ }^{\circ} \mathrm{C}$ em taxa de aquecimento de $5{ }^{\circ} \mathrm{C} / \mathrm{min}$, com permanência de $1 \mathrm{~h}$. Após o processo de sinterização, os corpos de prova foram submetidos a ensaios tecnológicos para determinação das propriedades físico-mecânicas: retração linear de queima (RLq); absorção de água, porosidade aparente e densidade parente, avaliadas através do método de Arquimedes utilizando-se como fluido de imersão a água na temperatura ambiente; e resistência à flexão (MRF) em três pontos, utilizando-se uma máquina universal de ensaios mecânicos (Shimadzu, AG-X 50 kN) operada à velocidade de $5 \mathrm{~mm} / \mathrm{min}$, com distância dos apoios de $35 \mathrm{~mm}$. Após os ensaios, os corpos de prova de cada composição foram submetidos ao processo de moagem e peneiramento em malha 200 mesh $(0,074 \mathrm{~mm})$ para posterior caracterização por difração de raios X (DRX). Para a identificação e quantificação das fases cristalinas, foi utilizado o programa Search Match: Untitled-XRD: Qualitative Analysis e os arquivos cristalográficos JCPDS do banco de dados PCPDFWIN do programa XRD6000 do difratômetro.

\section{RESULTADOS E DISCUSSÃO}

Análise química: a Tabela I mostra a composição química das amostras analisadas. Pôde-se observar que o percentual de dióxido de silício $\left(\mathrm{SiO}_{2}\right)$ variou de 51,07\% para a argila E a $63,90 \%$ para a argila C. Com relação ao teor de alumina $\left(\mathrm{Al}_{2} \mathrm{O}_{3}\right)$, os valores variaram de $21,49 \%$ para a argila $\mathrm{C}$ a $34,98 \%$ para a argila F. Para o óxido de ferro $\left(\mathrm{Fe}_{2} \mathrm{O}_{3}\right)$, notouse que a argila $\mathrm{C}$ apresentou o maior teor, $5,17 \%$, e a argila $\mathrm{F}$ o menor, $2,06 \%$. Os teores de $\mathrm{SiO}_{2}$ foram associados à presença de argilominerais e quartzo, enquanto os de $\mathrm{Al}_{2} \mathrm{O}_{3}$ foram relacionados à caulinita. A razão das frações de alumina e sílica $\left(\mathrm{Al}_{2} \mathrm{O}_{3} / \mathrm{SiO}_{2}\right)$ variou de 0,34 para a argila $\mathrm{C}$ e 0,67 para as argilas E e F; valores próximos de 1 indicam maior chance de ocorrer a formação da fase mulita em altas temperaturas. Na Tabela I ainda pode-se constatar que as frações de $\mathrm{Fe}_{2} \mathrm{O}_{3}, \mathrm{MgO}$ e $\mathrm{K}_{2} \mathrm{O}$ da argila $\mathrm{C}$ foram superiores às das demais argilas, podendo estar presentes em materiais que agem como fundentes durante a etapa de queima [18, 19]. A mica foi provavelmente a fonte da quantidade alta de potássio observada nas composições A e C, o que indicou uma possível ação fundente do $\mathrm{K}_{2} \mathrm{O}$ em baixas temperaturas, favorecendo a densificação [20]. Por outro lado, todas as amostras apresentaram baixos teores de $\mathrm{MgO}$, bem como quantidades mínimas ou ausência de $\mathrm{CaO}$ e $\mathrm{Na}_{2} \mathrm{O}$, o que é importante, pois esses óxidos podem atuar como fundentes durante o processo de queima, reagindo com fases amorfas e formando fases cristalinas que são mais estáveis frente à umidade [21, 22]. Com base nos dados da Tabela I, observouse que a argila $\mathrm{C}$ apresentou composição típica para cerâmica vermelha, com predominância de $\mathrm{SiO}_{2} \mathrm{e}_{2} \mathrm{O}_{3}$, bem como teor de óxido de ferro $\left(\mathrm{Fe}_{2} \mathrm{O}_{3}\right)$ superior a $5 \%$, o que indicou que a argila $\mathrm{C}$ pode apresentar, após queima, coloração vermelha, principalmente devido à oxidação do composto de 
Tabela I - Composições químicas (\% em massa) das argilas.

[Table I-Chemical compositions (wt\%) of the clays.]

\begin{tabular}{cccccccccc}
\hline Amostra & $\mathrm{PF}^{*}$ & $\mathrm{SiO}_{2}$ & $\mathrm{Al}_{2} \mathrm{O}_{3}$ & $\mathrm{Fe}_{2} \mathrm{O}_{3}$ & $\mathrm{MgO}$ & $\mathrm{TiO}_{2}$ & $\mathrm{~K}_{2} \mathrm{O}$ & $\mathrm{CaO}$ & $\mathrm{Na}_{2} \mathrm{O}$ \\
\hline Argila A & 6,33 & 60,82 & 26,01 & 2,65 & 0,95 & 1,24 & 2,12 & 0,12 & - \\
Argila B & 7,27 & 58,10 & 28,20 & 2,35 & 1,03 & 1,17 & 1,67 & 0,19 & - \\
Argila C & 4,60 & 63,90 & 21,49 & 5,17 & 1,25 & 1,06 & 2,39 & 0,11 & 0,09 \\
Argila D & 8,93 & 53,82 & 30,15 & 4,01 & 1,02 & 1,34 & 1,24 & - & 0,10 \\
Argila E & 9,30 & 51,07 & 34,42 & 2,67 & 1,13 & 1,22 & 0,98 & - & - \\
Argila F & 8,36 & 51,92 & 34,98 & 2,06 & 1,10 & 1,34 & 0,89 & 0,10 & 0,07 \\
\hline * PF - perda ao fogo. & & & & & & & &
\end{tabular}

ferro que ao final apresenta-se sob a forma de óxido férrico. Por outro lado, as argilas A, B, D, E e F possuem composição química típica para argilas plásticas aplicadas em cerâmica branca. Além disso, as mesmas apresentaram baixos teores de óxidos fundentes $\left(\mathrm{Na}_{2} \mathrm{O}\right.$ e $\left.\mathrm{K}_{2} \mathrm{O}\right)$ sendo um indicativo de alta refratariedade. Em relação à perda ao fogo, constatou-se que variou de 4,60\% para argila $\mathrm{C}$ a 9,30\% para a argila $\mathrm{E}$, sendo que estas perdas podem ser atribuídas provavelmente à evaporação de água, desidroxilação das massas e queima da matéria orgânica.

Análise granulométrica: a Tabela II e a Fig. 1 mostram resultados da distribuição granulométrica das seis amostras de argilas (A a F). Analisando as curvas da Fig. 1, verificouse que as seis argilas apresentaram distribuição de tamanho de partículas larga e multimodal. Observou-se, no geral, que a fração argila das amostras analisadas variou de 16,56\% para a amostra C a 34,68\% para a amostra E. A fração silte (diâmetro médio entre 2 e $20 \mu \mathrm{m}$ ) ficou na faixa de 52,73 a $70,49 \%$, e a areia (>20 um) entre 1,97 e $30,71 \%$. Verificouse também que a amostra $\mathrm{C}$ foi a que apresentou o maior diâmetro médio, e a amostra E, o menor, ou seja, a menos argilosa e a mais argilosa, respectivamente. Em síntese, a análise granulométrica mostrou que as massas estudadas são granulometricamente formadas com predomínio das frações silte mais areia. Os resultados obtidos pela análise granulométrica indicaram que todas as argilas estudadas são finas, o que contribui para maior sinterabilidade durante o processo de queima, devido à maior reatividade das partículas [23].

Tabela II - Composição granulométrica das argilas. [Table II - Granulometric composition of the clays.]

\begin{tabular}{ccccc}
\hline Amostra & $\begin{array}{c}\text { Argila }(\%) \\
(\mathrm{x} \leq 2 \mu \mathrm{m})\end{array}$ & $\begin{array}{c}\text { Silte }(\%) \\
(2<\mathrm{x} \leq 20 \mu \mathrm{m})\end{array}$ & $\begin{array}{c}\text { Areia }(\%) \\
(\mathrm{x}>20 \mu \mathrm{m})\end{array}$ & $\begin{array}{c}\text { Diâmetro } \\
\text { médio } \\
(\mu \mathrm{m})\end{array}$ \\
\hline Argila A & 21,55 & 67,58 & 10,87 & 9,20 \\
Argila B & 23,34 & 70,49 & 6,17 & 8,10 \\
Argila C & 16,56 & 52,73 & 30,71 & 14,47 \\
Argila D & 27,98 & 64,76 & 7,26 & 7,48 \\
Argila E & 34,68 & 63,35 & 1,97 & 5,50 \\
Argila F & 29,50 & 67,48 & 3,02 & 5,01 \\
\hline
\end{tabular}

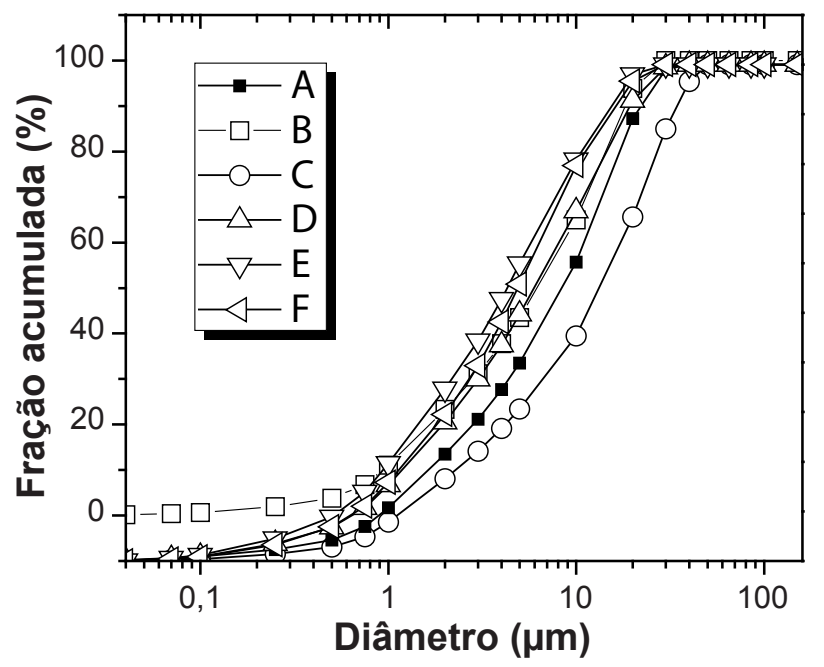

Figura 1: Distribuição granulométrica das amostras. [Figure 1: Particle size distribution of the samples.]

Índices de Atterberg e plasticidade: a Tabela III apresenta os valores de limite de plasticidade (LP), liquidez (LL) e índice de plasticidade (IP) das amostras analisadas. Observou-se que os limites LL e LP variaram de 36,1\% (Argila C) a 78,1\% (Argila E), e de 9,5\% (Argila F) a 45,8\% (Argila E), respectivamente. O IP situou-se entre 10,5\% (Argila C) a 33,5\% (Argila F). No geral, as argilas B, D, E e F são altamente plásticas (IP >15\%), sendo que as argilas E e F apresentaram valor superior a $30 \%$ no índice de plasticidade, indicando um elevado grau de plasticidade, o que indicou que pode ser necessário a adição de material não plástico para o seu processamento. Já as argilas A e C apresentaram plasticidade média $(7 \%<\mathrm{IP}<15 \%)$. Conforme a literatura [24], a partir do índice de plasticidade e do limite de plasticidade podem-se classificar as argilas em zona de extrusão ótima e zona de extrusão aceitável. Para uma extrusão aceitável a argila deve apresentar índice de plasticidade entre 10 e $34 \%$ e limite de plasticidade entre 18 e $31 \%$. No entanto, para uma extrusão ótima a argila deve apresentar índice de plasticidade entre 15 e $25 \%$, enquanto o limite de plasticidade deve estar entre 18 e $25 \%$. Observa-se na Tabela III que nenhuma das argilas apresentou LP e IP dentro da faixa ótima de extrusão, enquanto as argilas A, B e C apresentam LP e IP dentro da faixa de extrusão aceitável. 
Tabela III - Limites de Atterberg e índice de plasticidade das amostras.

[Table III - Atterberg limits of the samples.]

\begin{tabular}{cccc}
\hline Amostra & LL $(\%)$ & LP $(\%)$ & IP $(\%)$ \\
\hline Argila A & 37,5 & 25,0 & 12,5 \\
Argila B & 50,0 & 27,0 & 23,0 \\
Argila C & 36,1 & 25,7 & 10,5 \\
Argila D & 57,6 & 38,1 & 19,5 \\
Argila E & 78,1 & 45,8 & 32,3 \\
Argila F & 43,0 & 9,5 & 33,5 \\
\hline Nota: $I P=L L-L P$.
\end{tabular}

Análises térmicas (DTA e ATG): a Fig. 2 apresenta as curvas de termogravimetria (ATG) e análise térmica diferencial (DTA) das amostras analisadas. Observa-se na Fig. 2a, que as curvas de ATG apresentaram perda de massa total de $6,67 \%$ para a argila A, $7,96 \%$ para a argila B, $4,78 \%$ para a argila $C, 9,1 \%$ para a argila $D, 9,56 \%$ para a argila $E$ e $8,71 \%$ para a argila F. No geral, a perda de massa até 140 ${ }^{\circ} \mathrm{C}$ pode ser atribuída à perda das águas livre e adsorvida. Entre 140 e $600{ }^{\circ} \mathrm{C}$, a perda de massa correspondeu à oxidação da matéria orgânica e à desidroxilação das massas e, em seguida, acima de $600{ }^{\circ} \mathrm{C}$, a perda de massa foi essencialmente devido à oxidação da matéria orgânica [25, 26]. As perdas de massas foram confirmadas pela análise química, que apresentaram perdas ao fogo aproximadas aos valores encontrados nas análises termogravimétricas. Nas curvas de DTA, Fig. 2b, observou-se que as argilas C e D apresentaram pequenos picos exotérmicos próximo de $200{ }^{\circ} \mathrm{C}$, provavelmente decorrentes da queima de matérias orgânicas. Notou-se pico endotérmico em torno de $500^{\circ} \mathrm{C}$ nas amostras C e D, possivelmente decorrente da desidroxilação dos argilominerais e, posteriormente, picos exotérmicos próximos a $920{ }^{\circ} \mathrm{C}$, que podem estar relacionados com a nucleação de mulita. Observou-se que as argilas A, B, E e F na faixa de 500 a $510{ }^{\circ} \mathrm{C}$ apresentaram picos endotérmicos associados provavelmente à dexidroxilação dos argilominerais presentes nas argilas e picos exotérmicos entre $910 \mathrm{e} 980^{\circ} \mathrm{C}$ possivelmente associados à reorganização do material, com formação de fases cristalinas, devido à nucleação da mulita [27]. Ainda se verificou que as amostras A, B, E e F apresentaram bandas exotérmicas entre 240 e $302{ }^{\circ} \mathrm{C}$, sendo mais pronunciada na amostra A, que foram possivelmente relacionadas à queima da matéria orgânica.

Difração de raios $X(D R X)$ : a Fig. 3 ilustra as curvas de difração de raios $X$ das amostras estudadas. As amostras apresentaram basicamente as seguintes fases cristalinas: quartzo, caulinita, mica e esmectita. A caulinita é um importante componente de uma massa cerâmica, pois auxilia na conformação melhorando a trabalhabilidade das massas. Analisando-se os padrões de difração e a Tabela I, observouse que as amostras apresentaram caulinita mal cristalizada, uma vez que as intensidades dos picos de difração foram fracas, porém sua presença foi reforçada a partir do teor de
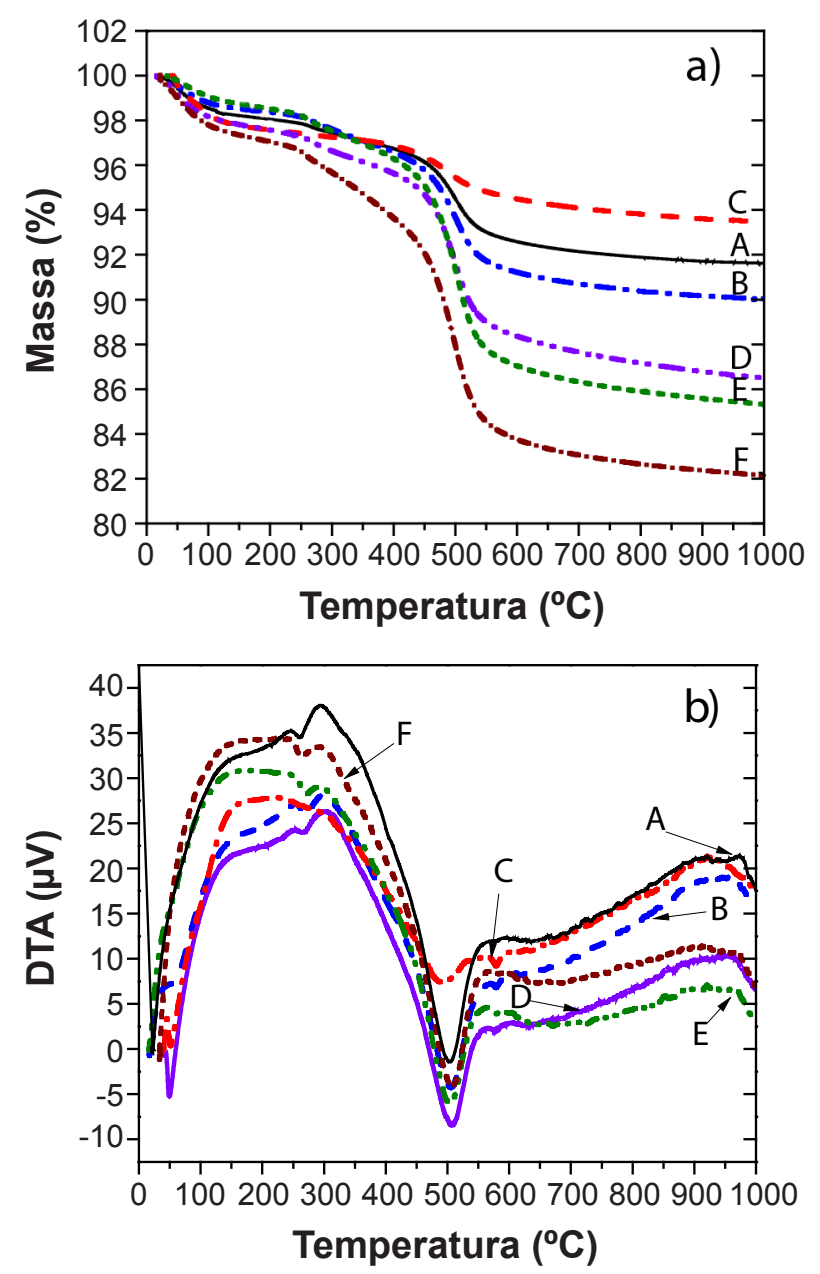

Figura 2: Curvas de ATG (a) e DTA (b) das amostras.

[Figure 2: TG (a) and DTA (b) curves of the samples.]

óxido de alumínio presente na composição química, bem como ao fato da inexistência de outras fontes de óxido de alumínio como gibsita ou boemita [3].

Propriedades físico-mecânicos: a Tabela IV apresenta as cores dos corpos de prova das argilas após queima a 850, 1000 e $1200{ }^{\circ} \mathrm{C}$ e o seu uso provável. Observou-se que as argilas A, $\mathrm{B}, \mathrm{D}, \mathrm{E}$ e F têm uso provável em cerâmica branca e fabricação de material, porém a argila $\mathrm{C}$ tem uso provável em cerâmica vermelha ou estrutural. As amostras A, E e F queimaram com cor branca para todas as faixas de temperatura; a amostra B queimou com cor branca em $850{ }^{\circ} \mathrm{C}$ e com cor creme em 1000 e $1200{ }^{\circ} \mathrm{C}$. A argila D apresentou queima com cor branca em 850 e $1200{ }^{\circ} \mathrm{C}$, porém em $1000{ }^{\circ} \mathrm{C}$ apresentou cor creme. No geral, as argilas A, B, D, E e F apresentaram variação na cor de creme claro ao branco, o que evidenciou teores insuficientes de ferro para promover cor avermelhada no produto final. Já a argila $\mathrm{C}$ foi a única que apresentou característica de argila para cerâmica vermelha, apresentando cor marrom avermelhado após queima a $850{ }^{\circ} \mathrm{C}$, laranja em $1000{ }^{\circ} \mathrm{C}$ e vermelha a $1200{ }^{\circ} \mathrm{C}$. No estudo [28] foi reportado que acima de $1000{ }^{\circ} \mathrm{C}$ ocorre a liberação de ferro bivalente, que por oxidação passa a ferro trivalente responsável pela cor vermelha, e acima de $1100{ }^{\circ} \mathrm{C}$ começa a ocorrer uma superqueima o ferro trivalente começa a reduzir gerando cor 


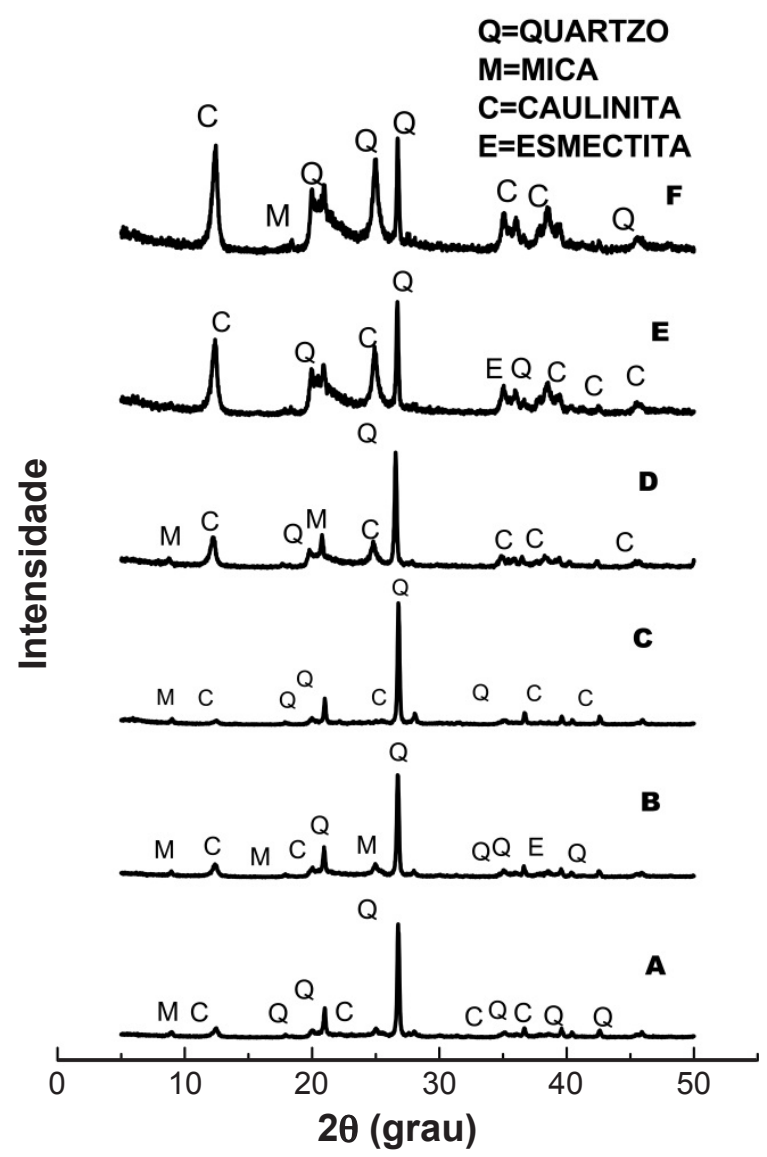

Figura 3: Difratogramas de raios $\mathrm{X}$ das amostras.

[Figure 3: X-ray diffraction patterns of the samples.]

marrom avermelhado. Entretanto, as aplicações citadas das argilas não podem se basear somente em cores, por isso, são analisadas posteriormente as propriedades físico-mecânicas e, consequentemente, confrontadas com as especificações.

A Fig. 4a apresenta os valores obtidos para retração linear após a queima entre 850 e $1200{ }^{\circ} \mathrm{C}$ das argilas investigadas. Observou-se que para todas as argilas ocorreu aumento da retração linear com o aumento da temperatura de queima. Tal comportamento pode estar relacionado ao maior grau de sinterização, difusão no estado sólido e formação de fase líquida, provocando aproximação das partículas e, portanto, reduzindo o volume dos corpos de prova [14, 29, 30]. Para $1200{ }^{\circ} \mathrm{C}$, as peças obtidas com as argilas apresentaram elevação mais pronunciada da retração linear, provavelmente em decorrência do maior empacotamento alcançado e à maior quantidade de fase líquida formada nesta temperatura, induzindo maior retração. Verificou-se que as argilas A, B, D, E e F apresentaram retração linear de queima dentro das especificações recomendadas para cerâmica branca que é no máximo 13\%, como também das especificações recomendadas pela indústria para grés sanitários que é de $12 \%$ e pela literatura $13 \%$ [31]. Por outro lado, a argila C apresentou resultado dentro da faixa aceitável para aplicações em cerâmica vermelha, apresentando retração linear entre 1,5 e $3,0 \%$, sendo que menor que $1,5 \%$ é referenciado como ideal [32].

A Fig. 4b apresenta os valores obtidos para absorção de água após a queima das argilas. Notou-se que a argila A apresentou o maior valor de absorção de água na faixa de 850 a $1000{ }^{\circ} \mathrm{C}$, enquanto a argila $\mathrm{C}$ o menor valor. Ainda se constatou que não ocorreu variação significativa da absorção de água na faixa de 850 a $1000{ }^{\circ} \mathrm{C}$ para as argilas A, B , C, E e F, com exceção da argila D, a qual apresentou uma redução da absorção de água de forma mais nítida. Observou-se no geral que o teor de absorção de água diminuiu com o aumento da temperatura. Tal fato é atribuído ao preenchimento dos poros devido à fusão dos óxidos fundentes presentes nas massas cerâmicas, o que promoveu redução da porosidade e, consequentemente, melhorou o empacotamento da peça [33], sendo mais pronunciada a redução da absorção de água nas argilas sinterizadas na faixa de 1000 a $1200{ }^{\circ} \mathrm{C}$. A argila $\mathrm{C}$, por conter maior quantidade de óxidos fundentes (particularmente $\mathrm{K}_{2} \mathrm{O}$ ) entre as argilas investigadas, foi a que apresentou a menor absorção de água. Conforme a literatura [4, 34, 35], o valor máximo de absorção de água para telhas é de $20 \%$, enquanto para tijolos e refratários é dentro da faixa de 8 a $22 \%$, sendo assim, o comportamento apresentando pela argila $\mathrm{C}$ na absorção de água foi dentro das especificações para produtos da indústria de cerâmica vermelha em todas as faixas de temperatura. Por outro lado, os resultados das argilas A, B, D, E e F foram conforme os requisitos para refratários densos, destacandose a amostra B por apresentar menor absorção de água entre as argilas claras, indicando que a mesma é menos propensa para apresentar patologias durante o uso. Entretanto, para aplicações como revestimentos de pisos e paredes, somente na faixa de 850 a $1000{ }^{\circ} \mathrm{C}$, as argilas B, E e F estão de acordo

Tabela IV - Cores dos corpos de prova após queima a 850,1000 e $1200{ }^{\circ} \mathrm{C}$.

[Table IV - Colors of the specimens after firing at 850, 1000 and $1200{ }^{\circ} \mathrm{C}$.]

\begin{tabular}{ccccc}
\hline Amostra & $850{ }^{\circ} \mathrm{C}$ & $1000{ }^{\circ} \mathrm{C}$ & $1200{ }^{\circ} \mathrm{C}$ & Uso provável \\
\hline Argila A & Branca & Branca & Branca & Refratário/louça \\
Argila B & Branca & Creme & Creme & Refratário/louça \\
Argila C & Marrom & Laranja & Vermelha & Tijolo/telha \\
Argila D & Branca & Creme & Branca & Refratário/louça \\
Argila E & Branca & Creme & Creme & Refratário/louça \\
Argila F & Branca & Branca & Creme & Refratário/louça \\
\hline
\end{tabular}



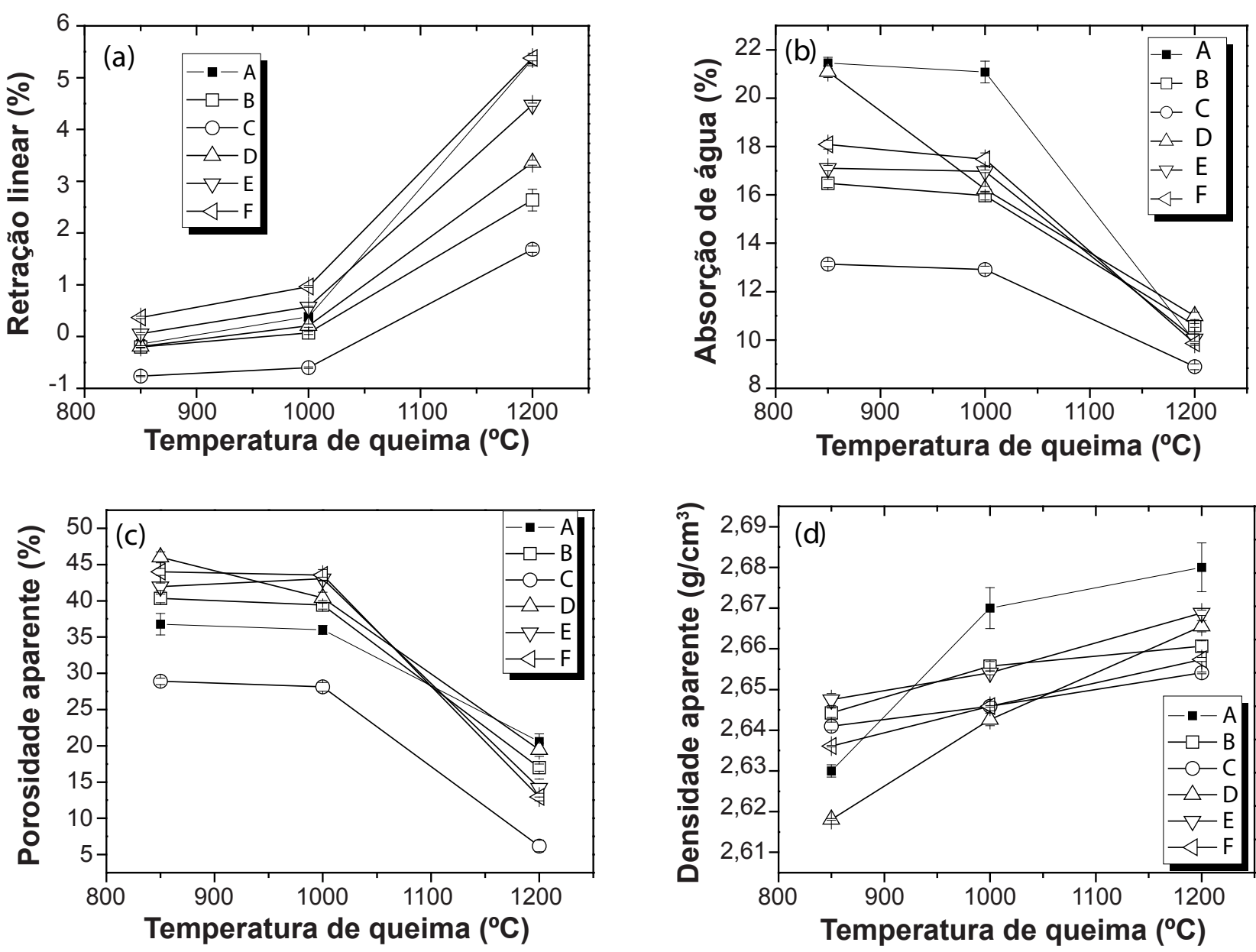

Figura 4: Resultados dos corpos de prova após queima: (a) retração linear de queima; (b) absorção de água; (c) porosidade aparente; (d) densidade aparente.

[Figure 4: Results of the specimens after firing: (a) linear firing shrinkage; (b) water absorption; (c) apparent porosity; (d) apparent density.]

com a exigência de absorção de água [32]. Esses resultados foram similares com os de absorção de água para argilas refratárias reportados na literatura [36,37].

A Fig. 4c mostra o comportamento da porosidade das argilas após a queima. Na faixa de 850 até $1000{ }^{\circ} \mathrm{C}$ não se observou queda significativa na porosidade aparente das argilas A, B, C, E e F, sendo a única exceção a argila $\mathrm{D}$, a qual teve uma queda mais evidente. Verificou-se que a partir de $1000{ }^{\circ} \mathrm{C}$ ocorreu intensificação na diminuição da porosidade aparente com o aumento da temperatura de queima, o que pode ser atribuído provavelmente a uma eficiente formação de fase liquida, retraindo a peça e reduzindo desta forma a porosidade [31]. Entretanto, como se trata de uma alta temperatura, pode ter ocorrido o crescimento das partículas por difusão de átomos das partículas menores para partículas maiores, o que diminuiu a porosidade aparente e, consequentemente, aumentou a densificação da amostra. As argilas A, B, D, E e F, por apresentarem coloração clara, apresentaram tendência para serem utilizadas como materiais refratários, por isso, torna-se conveniente analisar a porosidade. Conforme [38], verificouse que as argilas A, B, D, E, e F possuem características de materiais refratários silicoaluminosos, uma vez que o teor de $\mathrm{Al}_{2} \mathrm{O}_{3}$ está na faixa de 22 a 45,99\% (Tabela I). A respeito da porosidade dos refratários densos, os mesmos devem possuir uma porosidade total menor que $45 \%$, enquanto os

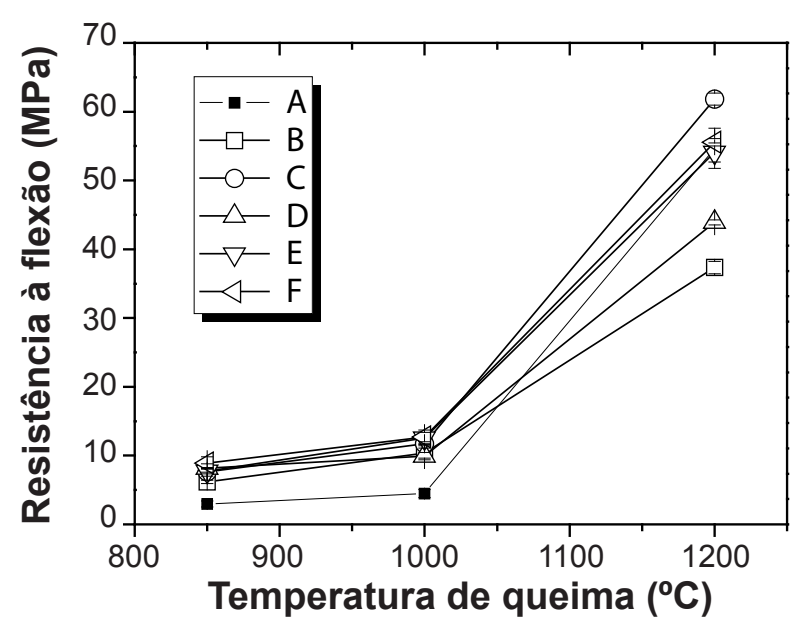

Figura 5: Resistência à flexão dos corpos de prova após queima. [Figure 5: Flexural strength of the specimens after firing.] 
refratários isolantes devem possuir uma porosidade total maior que $45 \%$ [39-42]. Sendo assim, praticamente todas as amostras (A, B, D, E e F) têm potencial para aplicação em materiais refratários densos, com exceção da amostra D na temperatura de $850{ }^{\circ} \mathrm{C}$ que apresentou características de refratário isolante (porosidade maior que 45\%).

A Fig. 4d apresenta os valores de densidade aparente para queimas a 850,1000 e $1200{ }^{\circ} \mathrm{C}$. Observou-se que a densidade aparente aumentou com o aumento da temperatura de sinterização para todas as argilas, sugerindo bom grau de sinterização das partículas que compõem as massas cerâmicas. Contatou-se que a densidade aparente foi máxima para todas as argilas quando atingiu $1200{ }^{\circ} \mathrm{C}$, na qual provavelmente ocorreu uma melhor compactação das partículas em função do maior nível de difusão e também da formação da fase líquida, promovendo maior densificação. Os valores obtidos na densidade aparente das argilas A, B, $\mathrm{D}, \mathrm{E}$ e $\mathrm{F}$, na faixa de 850 a $1200^{\circ} \mathrm{C}$, encontram-se dentro das especificações para argilas refratárias [43], enquanto que para a argila $\mathrm{C}$ o valor foi acima do mínimo recomendado
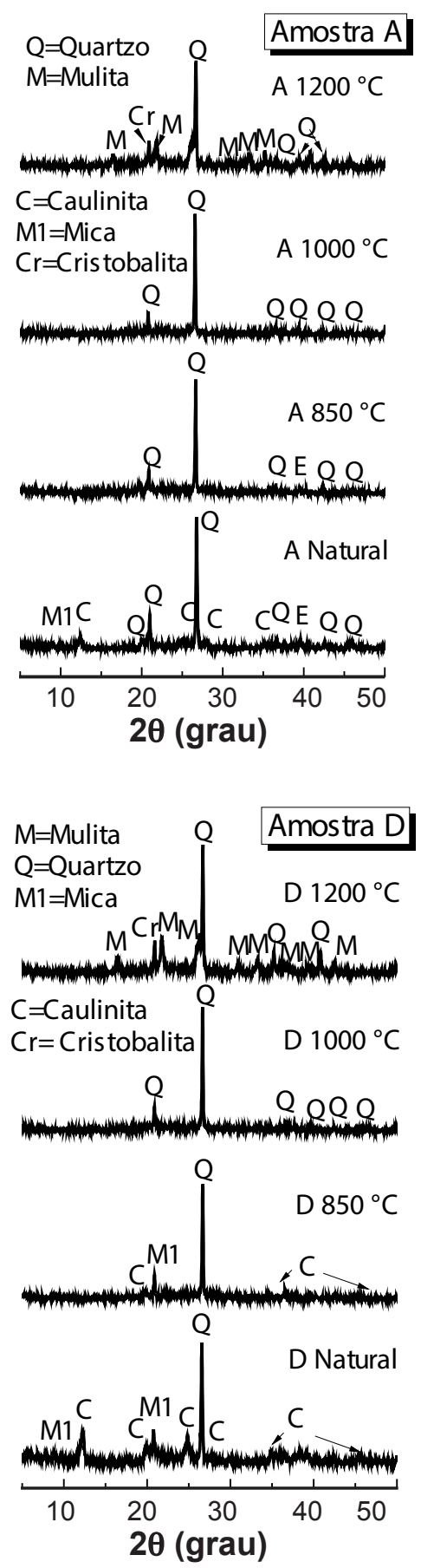
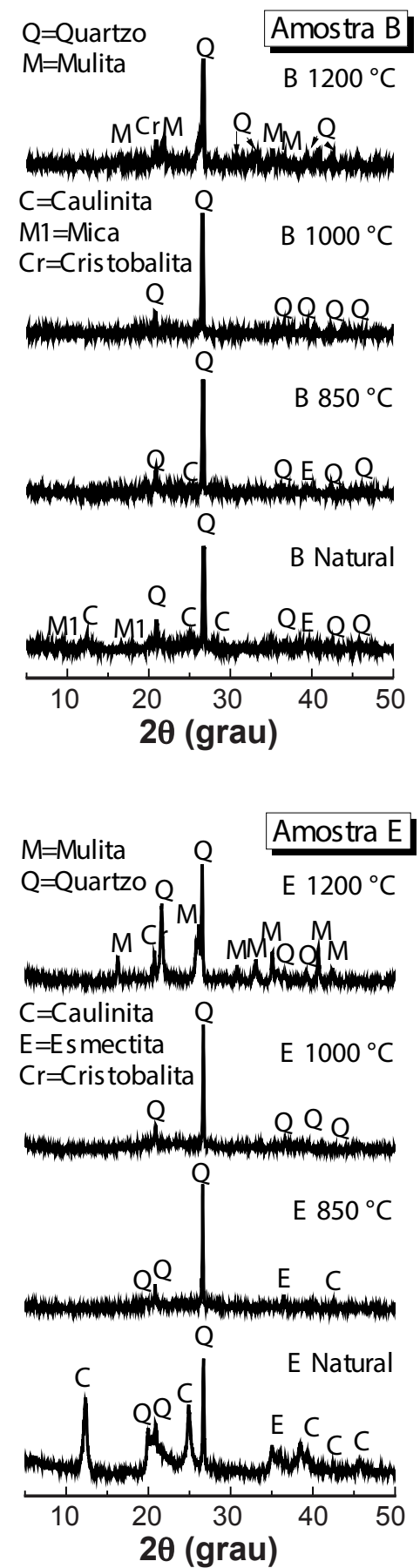
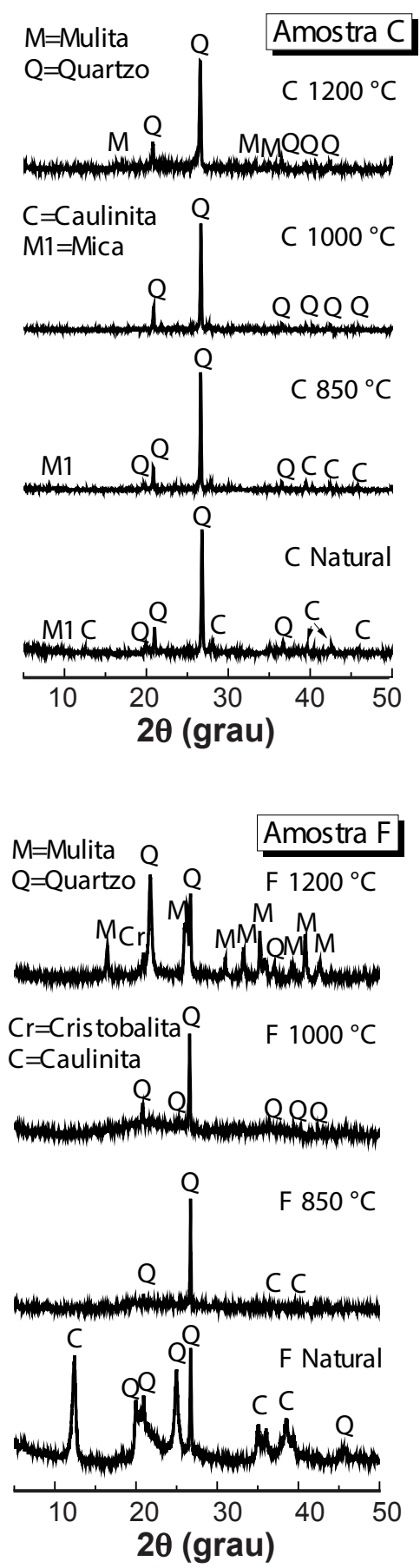

Figura 6: Difratogramas de raios $\mathrm{X}$ das amostras após queima a 850,1000 e $1200{ }^{\circ} \mathrm{C}$.

[Figure 6: X-ray diffraction patterns of the samples after firing at 850,1000 and $1200{ }^{\circ} \mathrm{C}$.] 
para cerâmica vermelha [4].

A Fig. 5 apresenta os valores obtidos para a resistência à flexão após queima dos corpos de prova obtidos com as argilas A a F. Constatou-se na faixa de 850 até $1000{ }^{\circ} \mathrm{C}$ aumento discreto na resistência à flexão de todas as argilas à medida que se elevou a temperatura de queima, sendo que a partir de $1000{ }^{\circ} \mathrm{C}$ começou a ocorrer a maximização da resistência, alcançando altos valores de resistência em $1200{ }^{\circ} \mathrm{C}$. Conforme [44], à medida que a temperatura de sinterização aumenta a resistência à flexão dos corpos de prova também aumenta, pois a elevação da temperatura reduz a quantidade de poros e, consequentemente, a resistência aumenta. Sendo assim, inferiu-se que o aumento na resistência mecânica pode ser justificado provavelmente pela redução da porosidade (Fig. 4c) e ao surgimento de novas fases cristalinas como a mulita (Fig. 6). As características mineralógicas e microestruturais das argilas são afetadas quando são submetidas ao aquecimento, uma vez que induz novas transformações de fases quando altas temperaturas são alcançadas e, consequentemente, auxiliando na elevação da resistência. Além disso, o aumento da resistência mecânica nas argilas investigadas foi associado à redução da porosidade nas peças, o que é desejável, pois o efeito deletério da porosidade sobre a resistência mecânica está fundamentalmente relacionado aos seguintes fatores: i) os poros reduzem a área da seção transversal na qual a carga é aplicada; e ii) os poros atuam como concentradores de tensão [45]. No geral, verificou-se que o aumento da temperatura para todas as argilas acarretou incrementos nos parâmetros de retração linear e resistência à flexão, com diminuição da absorção de água e da porosidade aparente, sendo a maximização em $1200{ }^{\circ} \mathrm{C}$. Provavelmente nesta temperatura, a maioria dos constituintes mineralógicos se fundiu e interligou as partículas [46]. Conforme [4, 47], os valores mínimos da tensão de ruptura à flexão recomendados para argilas de cerâmica vermelha são: 2,0 MPa para tijolos maciços, 5,5 MPa para blocos vazados e 6,5 MPa para telhas. Portanto, a argila $\mathrm{C}$ em toda a faixa de temperatura investigada, 850 até $1200{ }^{\circ} \mathrm{C}$, pode ser aplicada para produção de tijolos maciços, blocos vazados e telhas, uma vez que atende as especificações mínimas. Já os materiais refratários apresentam, tipicamente, resistência à flexão na faixa de valores entre 10 e $40 \mathrm{MPa}$ à temperatura ambiente. Por conseguinte, na temperatura de queima de $850{ }^{\circ} \mathrm{C}$ somente a argila $\mathrm{F}$ ficou no patamar aceitável para uso como refratário denso; já na temperatura de $1000^{\circ} \mathrm{C}$ as argilas B, D, E e F ficaram dentro das especificações para aplicação como refratário denso. Quando a sinterização foi a $1200{ }^{\circ} \mathrm{C}$, todas as argilas (A a F) apresentaram potencial de utilização para fabricação de refratários densos, mostrandose viável em termos de resistência mecânica $[48,49]$.

A Fig. 6 apresenta difratogramas de raios $\mathrm{X}$ das argilas após queima. A evolução das fases cristalinas presentes nas argilas A a $\mathrm{F}$ em função da temperatura de queima pode ser resumida da seguinte maneira: a $850{ }^{\circ} \mathrm{C}$ as fases cristalinas nas amostras foram mica, esmectita, quartzo e caulinita; a $1000{ }^{\circ} \mathrm{C}$ observou-se a presença de somente quartzo; já
Tabela V - Percentual de fases cristalinas após tratamento térmico a $1200{ }^{\circ} \mathrm{C}$.

[Table $V$ - Percentage of crystalline phases after heat treatment at $\left.1200{ }^{\circ} \mathrm{C}.\right]$

\begin{tabular}{ccccc}
\hline Amostra & Mulita & Quartzo & Cristobalita & Cristalinidade \\
\hline A & 32,52 & 53,33 & 0,00 & 85,86 \\
B & 43,33 & 40,06 & 5,12 & 88,53 \\
C & 30,35 & 54,81 & 0,00 & 85,17 \\
D & 43,68 & 34,68 & 5,45 & 83,82 \\
E & 51,50 & 26,35 & 9,93 & 87,80 \\
F & 54,25 & 13,11 & 11,33 & 78,70 \\
\hline
\end{tabular}

a $1200{ }^{\circ} \mathrm{C}$ foi possível observar picos de mulita, quartzo e cristobalita. Observou-se ainda que a $850{ }^{\circ} \mathrm{C}$ somente a argila $\mathrm{A}$ não apresentou picos característicos da caulinita, o que provavelmente foi relacionado à desidroxilação da estrutura da caulinita [50]. Ainda se pôde constatar que a destruição da estrutura cristalina da caulinita ocorreu em temperaturas abaixo de $1000^{\circ} \mathrm{C}$ para as todas as argilas, bem como a nucleação da mulita se intensificou depois de atingir $1200{ }^{\circ} \mathrm{C}$. A nucleação e crescimento dos cristais de mulita só foram observados a partir de $1100{ }^{\circ} \mathrm{C} \mathrm{em} \mathrm{[51].} \mathrm{Conforme}$ [52], a mulita é uma fase desejável que confere elevada resistência mecânica ao material cerâmico. A diminuição da intensidade dos picos de difração do quartzo indicou que ocorreu sua dissolução na fase líquida formada. Portanto, observou-se que em todas as amostras queimadas a 1200 ${ }^{\circ} \mathrm{C}$, constatou-se significativa presença de mulita, bem como diminuição na intensidade dos picos de difração do quartzo quando comparadas às intensidades de $1000{ }^{\circ} \mathrm{C}$. Sendo assim, provavelmente foi um fator decisivo a intensificação dos picos de mulita para a melhora da resistência à flexão para todas as amostras em $1200{ }^{\circ} \mathrm{C}$, quando comparadas aos valores de $1000{ }^{\circ} \mathrm{C}$.

$\mathrm{Na}$ Tabela V são apresentados os resultados da análise semiquantitativa das fases cristalinas presentes nas amostras estudadas. Observou-se que para a temperatura de 1200 ${ }^{\circ} \mathrm{C}$, as fases majoritárias foram mulita e quartzo para toda as amostras, com percentuais variando de 30,35 até $54,25 \%$ para a mulita, enquanto o quartzo variou de 13,11 até $54,81 \%$. Observou-se que o quartzo foi majoritário nas amostras A e C. Para as amostras B, D, E e F observouse baixo percentual de cristobalita e elevada quantidade de mulita, sendo o valor máximo de 54,25\% (amostra F). Isto pode estar relacionado com a importância da fase líquida no processo de cristalização da mulita [53]. Pôde-se verificar que praticamente todas as amostras apresentaram cristalinidade superior a $83 \%$, com exceção a amostra F que foi de $78,7 \%$ na temperatura de $1200{ }^{\circ} \mathrm{C}$.

\section{CONCLUSÕES}

A partir dos estudos sobre o potencial de argilas de diferentes camadas da região sul do estado do Amapá, pôdese concluir que as argilas apresentaram na sua composição 
mineralógica caulinita, quartzo, mica e esmectita. O tratamento térmico mostrou que, à medida que aumentou a temperatura de sinterização, todas as argilas aumentaram a retração linear e resistência à flexão, com diminuição da absorção de água e da porosidade aparente, sendo a maximização em $1200{ }^{\circ} \mathrm{C}$. A argila $\mathrm{C}$ apresentou coloração vermelha típica para aplicações em tijolos, blocos e telhas, sendo que as propriedades físico-mecânicas foram conforme as exigências desses produtos. Por outro lado, as argilas A, B, D, E e F apresentaram comportamento físico-mecânico compatível para o uso em cerâmica refratária densa. Os dados de composição química e mineralógica evidenciaram baixos teores de óxidos fundentes, favorecendo alta refratariedade por parte destas argilas. Entretanto, somente em $1200{ }^{\circ} \mathrm{C}$ qualquer uma das argilas A, B, D, E e F foram indicadas para aplicações como refratários densos, uma vez que se alcança altos valores de resistência. Todavia, em queima a $850{ }^{\circ} \mathrm{C}$ a argila $\mathrm{F}$ é aceitável para uso como refratário denso, já na temperatura de $1000{ }^{\circ} \mathrm{C}$ as argilas $\mathrm{B}, \mathrm{D}, \mathrm{E}$ e $\mathrm{F}$ alcançaram valores de resistência dentro das especificações. As argilas A, B, D, E e F contendo maior razão $\mathrm{Al}_{2} \mathrm{O}_{3} / \mathrm{SiO}_{2}$ e menor diâmetro médio de partículas foram as que apresentaram o melhor desempenho mecânico. Os cristais de mulita formados na sinterização a $1200{ }^{\circ} \mathrm{C}$ em todas as argilas auxiliaram também na elevação da resistência mecânica. No geral, as argilas A, B, D, E e F apresentaram características interessantes para utilização na indústria cerâmica, com a particularidade de ser refratária e ter cor de queima branca ou creme.

\section{AGRADECIMENTO}

Os autores agradecem a UFCG/CAPES (Coordenação de Aperfeiçoamento de Pessoal de Nível Superior) pela concessão de bolsa de estudo.

\section{REFERÊNCIAS}

[1] U.S. Prado, J.C. Bressiani, Ceram. Ind. 18, 1 (2013) 7.

[2] S.O. Ramos, R.S. Macedo, J.M. Cartaxo, R.R. Menezes, L.N.L. Santana, G.A. Neves, REMAP 5, 3 (2010) 65.

[3] R.S. Macedo, R.R. Menezes, G.A. Neves, H.C. Ferreira, Cerâmica 54, 332 (2008) 411.

[4] P.S. Santos, Ciência e tecnologia de argilas, $2^{\mathrm{a}}$ Ed., Edgar Blücher, S. Paulo (1992) 1.

[5] R.R. Menezes, P.M. Souto, L.N.L. Santana, G.A. Neves, R.H.G.A. Kiminami, H.C. Ferreira, Cerâmica 55, 334 (2009) 163.

[6] I.D.S. Pereira, I.A. Silva, J.M. Cartaxo, R.R. Menezes, L.N.L. Santana, G.A. Neves, H.C. Ferreira, Cerâmica 60, 354 (2014) 223.

[7] I.A. Silva, J.M.R. Costa, R.R. Menezes, H.S. Ferreira, G.A. Neves, H.C. Ferreira, Rev. Esc. Minas 66, 4 (2013) 485.

[8] D.M. Morais, R.M. Sposto, Ceram. Ind. 11, 5 (2006) 35. [9] A.P. Batista, R.R. Menezes, L.N. Marques, L.A. Campos, G.A. Neves, H.C. Ferreira, REMAP 4, 3 (2009) 64.
[10] M.J. Oliveira, Diagnóstico do setor mineral do estado do Amapá, JM Ed. Gráf., Macapá, Brasil (2010) 150.

[11] M.A. Valente, A.G.S. Campos, O.S. Watrin, Anais XVII Simp. Bras. Sensoriamento Remoto, João Pessoa, PB (2015) 3557.

[12] R.S. Macedo, R.R. Menezes, G.A. Neves, H.C. Ferreira, Cerâmica 54, 331 (2008) 373.

[13] G.P. Souza, S.J.G. Sousa, L.A.H. Terrones, J.N.F. Holanda, Cerâmica 51, 320 (2005) 381.

[14] B.J. Silva, R.R. Menezes, L.N.L. Santana, L.R.L. Melo, G.A. Neves, H.C. Ferreira, Matéria 17, 1 (2012) 919.

[15] C.B.B. Luna, D.F. Silva, E.M. Araújo, T.J.A. Mélo, A.D. Oliveira, Matéria 20, 2 (2015) 322.

[16] Assoc. Bras. Nor. Técn., NBR 6459, "Determinação do limite de liquidez - método de ensaio", Rio de Janeiro (1984).

[17] Assoc. Bras. Nor. Técn., NBR 7180, "Determinação do limite de plasticidade - método de ensaio", Rio de Janeiro (1984).

[18] W.P. Gonçalves, V.J. Silva, J. Gomes, R.R. Menezes, G.A. Neves, H.C. Ferreira, L.N.L. Santana, Cerâmica 60, 355 (2014) 316.

[19] I.P. Brito, E.P. Almeida, G.A. Neves, R.R. Menezes, V.J. Silva, L.N.L. Santana, Cerâmica 61, 360 (2015) 391.

[20] R.R. Menezes, R.R. de Almeida, L.N.L. Santana, H.S. Ferreira, G.A. Neves, H.C. Ferreira, Matéria 12, 1 (2007) 226.

[21] A.L. Silva, A.C. Chaves, G.A. Neves, D.N.S. Oliveira, C.B.B. Luna, P.S. Santos, Rev. Engenharia Tecno. 7, 3 (2015) 90.

[22] E. Facincani, Tecnologia Cerâmica - los Ladrillos, Faenza Ed. Iberica, Barcelona (1993) 263.

[23] H.H. Murray, Appl. Clay Sci. 17, 5 (2000) 207.

[24] C.V.P. Santos, A.R. Silva, M.A.S.G. Filho, E.F. Neto, A.A. Rabelo, Ceram. Ind. 17, 2 (2012) 25.

[25] L.G. Pedroti, J. Alexandrea, G.C. Xavier, S.N. Monteiro, C.M.F. Vieira, A.V. Bahiense, P.C.A. Maia, Ceram. Ind. 16, 1 (2011) 725.

[26] L.V. Amorim, J.D. Viana, K.V. Farias, M.I.R. Barbosa, H.C. Ferreira, Matéria 11, 1 (2006) 30.

[27] V.R. Batista, J.J.S. Nascimento, A.G.B. Lima, Matéria 14, 4 (2009) 1088.

[28] A.L. Texeira, D.C.M. Borges, J.A. Silva, N.M.M. Ferreira, M. Cargnin, Rev. Técnico Cient. 3, 1 (2012) 135.

[29] R.P.S. Dutra, M.L. Varela, R.M. Nascimento, U.U. Gomes, A.E. Martinelli, C.A. Paskocimas, Cerâmica 55, 333 (2009) 100.

[30] C.M.F. Vieira, S.N. Monteiro, Matéria 11, 3 (2006) 217. [31] V.S. Porto, M.F. Silva, T.B. Cruz, M.S.L. Cavalcanti, C.R. da Silva, REMAP 7, 1 (2012) 13.

[32] M. Dondi, Cerâm. Ind. 11, 3 (2006) 36.

[33] A.P. Ribeiro, M.P. Babisk, S.N. Monteiro, C.M.F. Vieira, Anais do 56 Congr. Bras. Cerâm., Curitiba, PR (2012) 756. [34] Assoc. Bras. Nor. Técn., NBR 15310, "Componentes cerâmicos - telhas - terminologia, requisitos e métodos de ensaio", Rio de Janeiro (2005).

[35] A.C. Masson, G. Renzi, S. Santos, R. Floriani, Rev. 
Maiêutica, Indaia 2l, 1 (2016) 7.

[36] W.P. Gonçalves, V.J. Silva, J. Gomes, G.A. Neves, R.R. Menezes, L.N. L. Santana. Mater. Sci. Forum 820, (2015) 46.

[37] M.G. Peralta-Sánchez, A.M. Morales-Carrera, A.F.D.C. Varajão, M.M. Ferreira, Cerâmica 57, 343 (2011) 254.

[38] Assoc. Bras. Nor. Técn., NBR 10237, "Materiais refratários - classificação", Rio de Janeiro (2001).

[39] Assoc. Bras. Nor. Técn., NBR ISO 8895, "Produtos refratários conformados isolantes - determinação da resistência à compressão a frio", Rio de Janeiro (2012).

[40] Assoc. Bras. Nor. Técn., NBR 6220, "Materiais refratários densos conformados - determinação da densidade de massa aparente, porosidade aparente, absorção e densidade aparente da parte sólida", Rio de Janeiro (1997).

[41] Assoc. Bras. Nor. Técn., NBR 8003, "Materiais refratários isolantes conformados - determinação da porosidade total", Rio de Janeiro (1997).

[42] Assoc. Bras. Nor. Técn., NBR 8592, "Materiais refratários densos granulados - determinação da densidade de massa aparente, da absorção e da porosidade aparente método de ensaio", Rio de Janeiro (1995).

[43] L.H.V. Vlack, Propriedades dos materiais cerâmicos, Edgar Blücher, S. Paulo (1973) 1.
[44] R.A. Júnior, R.P.S. Dutra, L.F.A. Campos, H.S. Ferreira, R.M. Nascimento, S.J.G. Lima, REMAP 7, 2 (2012) 117.

[45] B.C.A. Pinheiro, J.N.F. Holanda, Cerâmica 56, 339 (2010) 237

[46] M.A.F. Melo, S.G. Neto, D.M.A. Melo, L.P. Carvalho, J.N. Galdino, S.A.G. Silva, Cerâmica 48, 308 (2002) 183.

[47] M.E.A. Carreiro, R.C. Santos, V.J. Silva, H.L. Lira, G.A. Neves, R.R. Menezes, L.N.L. Santana, Cerâmica 62 , 362 (2016) 170.

[48] R.C. Bradt, in: Refractories handbook, C.A. Schacht, Ed., Marcel Dekker, New York (2004) 11.

[49] F.N. Cunha-Duncan, R.C. Bradt, Cerâmica 49, 312 (2003) 199.

[50] H.S. Santos, P. Kiyohara, A.C.V. Coelho, P.S. Santos, Cerâmica 52, 322 (2006) 125.

[51] M.S. Conconi, M.R. Gauna, M.F. Serra, G. Suarez, E.F. Aglietti, N.M. Rendtorff, Cerâmica 60, 356 (2014) 524.

[52] C.M.F. Vieira, S.N. Monteiro, Cerâmica 49, 309 (2003) 6.

[53] J.M. Cartaxo, P.M. Bastos, L.N.L. Santana, R.R. Menezes, G.A. Neves, H.C. Ferreira, Cerâmica 62, 364 (2016) 338.

(Rec. 21/06/2016, Rev. 19/09/2016, 06/11/2016, 17/04/2017, 12/05/2017, Ac. 21/05/2017) 